\title{
Integrated multi-trophic aquaculture systems: energy transfers and food web organization in coastal earthen ponds
}

\author{
Sofia Gamito1,2,* $^{1,}$ Hugo Quental-Ferreira ${ }^{3}$, Aida Parejo ${ }^{3}$, Joël Aubin ${ }^{4}$, \\ Villy Christensen ${ }^{5}$, Maria Emília Cunha ${ }^{3}$ \\ ${ }^{1}$ CCMAR, Centre of Marine Sciences, Universidade do Algarve, Campus de Gambelas, 8005-139 Faro, Portugal \\ ${ }^{2}$ FCT, Faculdade de Ciências e Tecnologia, Universidade do Algarve, Campus de Gambelas, 8005-139 Faro, Portugal \\ ${ }^{3}$ EPPO, Estação Piloto de Piscicultura de Olhão, Instituto Português do Mar e da Atmosfera, Quinta de Marim, \\ 8700-194 Olhão, Portugal \\ ${ }^{4}$ INRA UMR SAS, 35042 Rennes Cedex, France \\ ${ }^{5}$ Institute for the Oceans and Fisheries, University of British Columbia, Vancouver, BC V6T 1Z4, Canada
}

\begin{abstract}
Three Ecopath models were built to reproduce 3 experimental treatments carried out in earthen ponds located in Olhão, southern Portugal, to understand the energy transferred and the ecosystem state in integrated multi-trophic aquaculture (IMTA). These earthen ponds behave as simplified ecosystems or mesocosms, with well-defined borders, where the relationships between trophic groups can be described through ecosystem modeling. Different combinations of species were produced in these ponds, corresponding to the 3 treatments: (1) fish, oysters and macroalgae (FOM); (2) fish and oysters (FO); and (3) fish and macroalgae (FM). The managed species were meagre Argyrosomus regius, white seabream Diplodus sargus, flathead grey mullet Mugil cephalus, Japanese oyster Crassostrea gigas and sea lettuce Ulva spp. The results showed that the total amount of energy throughput was 15 to 17 times higher when compared with an equivalent naturalized system. The high biomass and low recycling indicated an immature system with low resilience and low stability that demands high rates of water renewal and aeration to maintain good water-quality levels for finfish production. The addition of oysters and macroalgae in the FOM treatment appeared to improve the water quality, since oysters controlled the excess of phytoplankton produced in the ponds by ingesting a fair amount of the phytoplankton, while the macroalgae helped in the absorption of excess nutrients and created a habitat for periphyton and associated macroinvertebrates. Some ecosystem attributes of the FOM ponds approached the values of the naturalized model, suggesting a possible path towards more sustainable aquaculture.
\end{abstract}

KEY WORDS: Integrated multi-trophic aquaculture systems - IMTA - Earthen pond ecosystems · Ecosystem energy transfer $\cdot$ Ecopath models $\cdot$ Sustainable aquaculture

\section{INTRODUCTION}

Marine fish farming in coastal earthen ponds is one of the main aquaculture systems used in southwest European countries. The most used commercial fish

${ }^{*}$ Corresponding author: sgamito@ualg.pt species are gilthead seabream Sparus aurata and sea bass Dicentrarchus labrax, reared under semi-intensive conditions (Valente et al. 2006, Anras et al. 2010). Production levels are low, at around 2 to $3 \mathrm{~kg} \mathrm{~m}^{-3}$ at the end of the production cycle (Ferreira et al. 2010). 
Additionally, production costs are often too high to offer sustainable economic activity (high labor, energy and land costs). Since most farms are located in environmentally sensitive areas, the adaptation of the principles of integrated multi-trophic aquaculture (IMTA) to the actual production may prove to be worthwhile and commercially viable. Semi-intensive multi-trophic polyculture in earthen ponds can guarantee an important competitive advantage for local holdings, in particular, in terms of the diversification and appreciation of their products, while maintaining the ecological resilience of the ecosystems.

IMTA is under development all over the world for use in sustainable seafood production (Soto 2009, Chopin 2012, Rosa et al. 2020). Multi-trophic aquaculture refers to the incorporation of species from different nutritional levels in the same production system (Chopin et al. 2008, Barrington et al. 2009). In these systems, species with different trophic levels are produced together either in the same or in separated compartments, with the effluent cascading between them (Bostock et al. 2010). The aim is to increase profit while reducing organic and nutrient loadings into the environment (Ren et al. 2012). Primary producers (macroalgae and/or phytoplankton) will benefit from the excess nutrients introduced in the system by artificially feeding on some of the species, which will also enhance filter and detritus feeders. Therefore, in these systems, besides the profit from the commercial production of fed organisms, there is also production of other non-fed organisms, like detritivores, filter feeders and primary producers, that will help to clean up the system and to maintain good water quality (Granada et al. 2016, Rosa et al. 2020), overall improving the sustainability of the aquaculture system.

IMTA in earthen ponds is firmly within the objectives of the ecosystem approach to aquaculture (EAA) by integrating aquaculture within the wider ecosystem and can be regarded as a strategy to make aquaculture contribute to sustainable development (Soto et al. 2008). To be put into practice, such a strategy requires an understanding of the major ecological interactions involved with IMTA systems and the possibility to predict consequences of the different integration alternatives as well as management practices. Ecological models can be used to support this step as far as ecological objectives are involved. Furthermore, the evaluation of different scenarios can be used towards assessing the carrying capacity and optimizing IMTA.

One of several possible approaches is the use of Ecopath with Ecosim (EwE) software. This is a tool for constructing models of trophic interactions and can be used to evaluate the 'health' of the whole system (Christensen 1998). EwE modeling defines the ecosystem components and parameterization where energy or mass is assumed to be conserved; the energy input to any group or species in the model must equal the energy output from that group or species (Christensen 2009). For all groups included in the model, the sum of production, unassimilated food and respiration equals the consumption; production is further split into catch, predation, other mortality, biomass accumulation and net migration (Christensen 2009).

Ecosystem modeling with EwE has been used to describe and compare food webs, with a focus on aspects such as complexity and energy transfer, or to assess the effects of environmental changes or of fishery pressure, and evaluate impacts of dredging or of marine protected areas (e.g. Steenbeek et al. 2014, Hyder et al. 2015). So far, >400 EwE models have been published, applied to an extensive variety of ecosystems, including polar regions and terrestrial systems, and to a broad range of research topics, comprising pollution, aquaculture and marine protected areas (Colléter et al. 2015). Comparisons between systems can help to determine the trophic state or the development needs of the system concerned (Brando et al. 2004 and references therein). The application of an EwE model to a fishpond aquaculture system is of importance not only to interpret the ecosystem functioning but also to recommend a more suitable management approach (Zhou et al. 2015).

Earthen ponds behave as simplified ecosystems, where the main trophic levels are primary producers (feed included), and consumers, such as zooplankton, benthic macroinvertebrates and fish. In pond IMTA, some species are amplified (the species produced) and others are excluded, such as top predators like fish and birds. In these ecosystems with well-defined borders, the relationships between trophic groups can be observed and tested through network analysis and simulations. The ecosystem established within IMTA ponds is highly artificialized, and we explore how IMTA could be improved by comparing the ecosystem attributes and energy transferred among the trophic levels within 3 Ecopath models, corresponding to 3 experimental treatments: (1) fish, oysters and macroalgae (FOM); (2) fish and oysters (FO); and (3) fish and macroalgae (FM) (Cunha et al. 2019a,b), with a more natural extensive pond system (Gamito \& Erzini 2005). 


\section{MATERIALS AND METHODS}

\subsection{IMTA experiments}

Three IMTA experiments were carried out in duplicate earthen ponds of about $500 \mathrm{~m}^{2}$ area and $1.5 \mathrm{~m}$ depth, each located at the Aquaculture Research Station of the Portuguese Institute of Sea and Atmosphere, southern Portugal $\left(37^{\circ} 2^{\prime} \mathrm{N}, 7^{\circ} 49^{\prime} \mathrm{W}\right.$ ) (Cunha et al. 2019a,b). The experiments lasted during 1 production cycle (April to November 2016) and comprised the growth and production of 3 fish species raised together with oysters and macroalgae (treatment FOM) or raised without 1 of these last 2 groups (treatments FO and FM).

The fish species were: meagre Argyrosomus regius (Asso, 1801), white seabream Diplodus sargus (Linnaeus, 1758) and flathead grey mullet Mugil cephalus Linnaeus, 1758. The oysters were triploids of Crassostrea gigas (Thunberg, 1793), and the macroalgae were mainly sea lettuce belonging to the genus Ulva. Table 1 presents the initial number and the initial and final mean weight of individuals introduced into the ponds. Besides these organisms, there was phytoplankton that naturally develop in the ponds, and also periphyton, which is a complex mixture of algae, cyanobacteria, heterotrophic microbes and detritus, which grow over all submerged pond surfaces including the macroalgae (Azim et al. 2005). In the FO treatment, macroalgae proliferation was controlled weekly by harvesting the excess, while in the FOM and FM treatments, the macroalgae were partly removed every 2 wk.

Except for grey mullet juveniles, which had a wild origin, all fish were produced at the Aquaculture Research Station hatchery. Fish were introduced at the end of March/beginning of April and a small number were regularly sampled for length-weight measurements as a basis for estimating the feed size and amount of ration to deliver daily. This amount also took into consideration the water temperature in the pond. Fish were fed a commercial fish diet (for details on the feed composition, see Cunha et al. $2019 b)$. Growth performance of fish was determined at the beginning, middle and end of the experiment by sampling 50 individuals of each species from each pond.

Oysters were seeded in the middle of May. They were farmed in traditional oyster mesh bags suspended close to the pond surface which were airexposed every week for $24 \mathrm{~h}$ to avoid biofouling. Oyster growth and mortality were monitored monthly and dead individuals removed. Oysters were sorted and re-distributed to new bags (1 bag divided in 2) whenever the mesh bag attained $8 \mathrm{~kg}$ or oyster volume was $80 \%$ of the mesh bag.

Macroalgae occurred naturally in the ponds, and to control the proliferation in treatment FO, floating macroalgae were harvested manually with a fishing net every week. In the treatments FOM and FM, the harvesting occurred every other week. After harvesting, macroalgae were washed with clean saltwater to remove most of the impurities and epibionts and weighed after being hand-squeezed. Macroalgae growing at the bottom were not removed to avoid disturbances to the system (sediment resuspension and fish stress).

Daily water renewal in the ponds varied between 40 and $100 \%$ and was managed as a compromise to maintain the water quality for the fish while still retaining enough phytoplankton to feed the oysters (Cunha et al. 2019b). Once a week, $<1 \%$ of the bottom water was purged to prevent excess organic matter from accumulating.

\subsection{Model construction and parameterization}

\subsubsection{General structure}

Ecopath basic data requirements are estimates of biomass and production:biomass (P:B) and consumption:biomass (C:B) ratios for each trophic group, and the diet compositions (Christensen et al. 2005). Alternatively, 1 of the first 3 input requirements can be estimated by EwE if ecotrophic efficiency (EE) or a production:consumption $(\mathrm{P}: \mathrm{C})$ ratio of that group is included (Christensen et al. 2005). EE that is usually estimated by the model gives the proportion of the production that is harvested or predated upon (Arreguín-Sanchez et al. 1993). The model should include the main species and functional groups and

Table 1. Number and weight of fish and oysters introduced into the 3 types of experimental pond. FOM: fish, oysters and macroalgae; FO: fish and oysters; FM: fish and macroalgae; meagre: Argyrosomus regius; seabream: Diplodus sargus; mullet: Mugil cephalus; oyster: Crassostrea gigas

\begin{tabular}{|lrrrrr|}
\hline & \multirow{2}{*}{$\begin{array}{c}\text { Initial } \\
\text { number }\end{array}$} & \multirow{2}{*}{$\begin{array}{c}\text { Average } \\
\text { initial }\end{array}$} & \multicolumn{4}{c|}{$\begin{array}{c}\text { Average final } \\
\text { wer poight (g) }\end{array}$} \\
& per pond & weight (g) & FOM & FO & FM \\
\hline Meagre & 1450 & 204.5 & 579.8 & 599.8 & 418.9 \\
Seabream & 850 & 51.5 & 188.5 & 159.5 & 174.4 \\
Mullet & 564 & 117.6 & 213.0 & 159.9 & 193.1 \\
Oyster & 18000 & 0.5 & 53.3 & 64.7 & \\
& & & & & \\
\hline
\end{tabular}


the trophic levels involved and relevant to the ecosystem under consideration (Heymans et al. 2016).

Following these guidelines, 3 Ecopath models were built on data provided by each experimental treatment involving trophic links and energy transfer among 12 to 13 functional groups referred to in Table 2, which shows the input data to the EwE model built for the FOM treatment. The first 3 functional groups correspond to the produced fish species: meagre (carnivores), white seabream (omnivores) and mullets (detritovores). Oysters (filter feeders) were included as a $4^{\text {th }}$ group in the 2 models involving oyster culture. Macroinvertebrates were separated into Crustacea, Gastropoda, Bivalvia and Annelida to allow direct comparison with a previous model of a naturalized earthen pond (Gamito \& Erzini 2005). The next 3 functional groups correspond to zooplankton, macroalgae (together with periphyton) and phytoplankton. The last functional group was the detritus group; the software always includes this group in the models. Feed (pellets) was defined as a detritus functional group because it is neither a producer nor a consumer, but supports the food web as a food source (Bayle-Sempere et al. 2013), and was considered as an import, following Ruddle \& Christensen (1993). All functional groups contribute to the detritus group and the portion of the detritus that is not consumed is exported out of the system or accumulated (Christensen et al. 2005).

The software enables the calculation of a pedigree index - an index that evaluates the quality and uncertainty of the input and output parameters included

Table 2. Input data for the fish, oysters and macroalgae (FOM) model. P: production; B: biomass; C: consumption; U: unassimilated; Bold: values that were kept equal in all models

\begin{tabular}{|c|c|c|c|c|c|c|}
\hline $\begin{array}{l}\text { Functional } \\
\text { group }\end{array}$ & $\begin{array}{l}\text { Biomass in } \\
\text { habitat area } \\
\qquad\left(\mathrm{g} \mathrm{m}^{-2}\right)\end{array}$ & $\begin{array}{c}\mathrm{P}: \mathrm{B} \\
\left(8 \mathrm{mo}^{-1}\right.\end{array}$ & $\begin{array}{c}\mathrm{C}: \mathrm{B} \\
\left(8 \mathrm{mo}^{-1}\right)\end{array}$ & $\mathrm{P}: \mathrm{C}$ & U:C & $\begin{array}{c}\text { Detritus } \\
\text { import } \\
\left(\mathrm{g} \mathrm{m}^{-2} 8 \mathrm{mo}^{-1}\right)\end{array}$ \\
\hline Meagre & 1116.875 & 1.011 & 2.989 & & 0.2 & $\mathbf{0}$ \\
\hline Seabream & 204.624 & 1.294 & 3.181 & & 0.2 & $\mathbf{0}$ \\
\hline Mullet & 186.447 & 0.578 & & 0.2 & 0.4 & $\mathbf{0}$ \\
\hline Oyster & 217.576 & 3.37 & & 0.2 & 0.4 & $\mathbf{0}$ \\
\hline Crustacea & 4.416 & 4.93 & & 0.2 & 0.4 & $\mathbf{0}$ \\
\hline 6 Gastropoda & 1.701 & 1.81 & & 0.2 & 0.4 & $\mathbf{0}$ \\
\hline 7 Bivalvia & 11.112 & 2.71 & & 0.2 & 0.4 & $\mathbf{0}$ \\
\hline 8 Annelida & 25.991 & 5.24 & & 0.2 & 0.4 & $\mathbf{0}$ \\
\hline 9 Zooplankton & 0.918 & 60 & & 0.2 & 0.4 & $\mathbf{0}$ \\
\hline $\begin{array}{l}10 \text { Macroalgae } \\
\text { and periphyton }\end{array}$ & 45.019 & 27.972 & & & & $\mathbf{0}$ \\
\hline 11 Phytoplankton & 12.405 & 250 & & & & $\mathbf{0}$ \\
\hline 12 Feed & 18.879 & & & & & 4720 \\
\hline 13 Detritus & 19 & & & & & $\mathbf{0}$ \\
\hline
\end{tabular}

in the 3 models. To estimate this index, parameters assessed directly from experimental data, such as biomass and $\mathrm{P}: \mathrm{B}$ ratios of fish, were considered to have high precision, while other parameters, such as biomass and P:B ratio of phytoplankton, were classified as having low precision, since they were estimated by indirect methods. The biomass in the IMTA models used wet weight (WW) values for all functional groups. Considering the small size of the ponds and the period of time used (1 production cycle $=8 \mathrm{mo}$ ), the units adopted throughout this work were $\mathrm{g} \mathrm{m}^{-2}$ and $\mathrm{g} \mathrm{m}^{-2} 8 \mathrm{mo}^{-1}$.

\subsubsection{Diet composition matrix and} estimation of production:consumption and unassimilated:consumption ratios

Similar diet composition matrices were considered in the 3 models (FOM, FO and FM) (Table 3). The fish diet was based on field observations and on fatty acid and stable isotope analysis. Meagre and seabream ate almost exclusively formulated feed, while grey mullets ate a large variety of food items. According to field observations, white seabream was occasionally seen eating where macroalgae/periphyton accumulate. Grey mullets were frequently seen eating at the surface film and close to the macroalgae surface, where periphyton and associated macroinvertebrates develop and the debris tend to accumulate. In the models, a large percentage of the oyster diet $(70 \%)$ relied on phytoplankton availability. However, some debris from uneaten feed, together with detritus and suspended particles, were also included in their diet (Table 3). For the other functional groups, the diets included in Table 3 are explained in the next 2 subsections.

Since there was no data on the consumption rates for grey mullets, macroinvertebrates, oysters and zooplankton, no $\mathrm{C}: \mathrm{B}$ ratios were introduced for these groups. Instead, a P:C ratio of 0.2 was assumed, while keeping the same values in the 3 models (Table 2). A P:C ratio close to 0.3 represents consumption 3 times higher than production, which is common in smaller predators; lower P:C values imply higher relative consumptions (Christensen et al. 2005). 
Table 3. Input diet composition matrix. Columns state the diet of each functional group. Column headings correspond to row headings

\begin{tabular}{|lccccccccc|}
\hline & 1 & 2 & 3 & 4 & 5 & 6 & 7 & 8 & 9 \\
\hline 1 Meagre & 0 & 0 & 0 & 0 & 0 & 0 & 0 & 0 & 0 \\
2 Seabream & 0 & 0 & 0 & 0 & 0 & 0 & 0 & 0 & 0 \\
3 Mullet & 0 & 0 & 0 & 0 & 0 & 0 & 0 & 0 & 0 \\
4 Oyster & 0 & 0 & 0 & 0 & 0 & 0 & 0 & 0 & 0 \\
5 Crustacea & 0 & 0.005 & 0.02 & 0 & 0 & 0 & 0 & 0.01 & 0 \\
6 Gastropoda & 0 & 0 & 0.005 & 0 & 0 & 0 & 0 & 0 & 0 \\
7 Bivalvia & 0 & 0 & 0.01 & 0 & 0 & 0 & 0 & 0.01 & 0 \\
8 Annelida & 0 & 0 & 0.01 & 0 & 0 & 0 & 0 & 0.02 & 0 \\
9 Zooplankton & 0 & 0 & 0.1 & 0 & 0 & 0 & 0 & 0 & 0 \\
10 Macroalgae & 0 & 0.01 & 0.3 & 0 & 0.5 & 0.4 & 0 & 0 & 0 \\
$\quad$ and periphyton & & & & & & & & & \\
11 Phytoplankton & 0 & 0 & 0 & 0.7 & 0.2 & 0 & 0.5 & 0.02 & 0.8 \\
12 Feed & 1 & 0.985 & 0.1 & 0.15 & 0.1 & 0.1 & 0.1 & 0.1 & 0.1 \\
13 Detritus & 0 & 0 & 0.455 & 0.15 & 0.2 & 0.5 & 0.4 & 0.84 & 0.1 \\
$\quad$ Import & 0 & 0 & 0 & 0 & 0 & 0 & 0 & 0 & 0 \\
$\quad$ Sum & 1 & 1 & 1 & 1 & 1 & 1 & 1 & 1 & 1 \\
& & & & & & & & & \\
\hline
\end{tabular}

duction was considered as total biomass accumulation since they were harvested only at the end of the experiment (Table 4).

The amount of feed given varied with the size of fish, the total fish biomass in the pond, and the water temperature. Since meagre and white seabream fed almost exclusively on formulated feed (Brito 2018, Nahon et al. 2018), their C:B ratios were estimated from the amount of feed given (Table S3 \& Text S2).

Grey mullets have a diversified diet, eating only a small portion of the artificial feed, as found in fatty acids and isotope analysis (Brito 2018, Nahon et al. 2018). Since their diet is diversified, it was not possible to estimate the C:B ratio.

Unassimilated food was estimated as the difference between consumption and production (Christensen et al. 2005). Those authors suggested a default unassimilated:consumption ratio of 0.2 for carnivorous fish, while for herbivores, such as some zooplankton and macroinvertebrate species, the proportion of unassimilated food may be up to 0.4 . Unassimilated:consumption ratios of 0.4 were given to all functional groups other than meagre and seabream (Table 2).

\subsubsection{Produced species: meagre,} white seabream, mullets and oysters

The average biomasses of meagre, seabream, mullets and oysters were estimated based on the equations presented in Tables S1 \& S2 in the Supplement at www.int-res.com/articles/ suppl/q012p457_supp.pdf, and the P:B ratios were estimated as the sum of the $\mathrm{P}: \mathrm{B}$ daily ratios (see Text $\mathrm{S} 1$ for detailed explanations of model development). Meagre final production was lower in the FM treatment and consequently the P:B ratio was also lower (Table 4). For the other 2 fish species, some variations in production were also observed, with lower production in the FO treatment. The final fish pro-
Table 4. Input parameters for the functional groups, based on experimental data from each treatment. P:B: production:biomass ratio; C:B: consumption:biomass ratio; FOM: fish, oysters and macroalgae; FO: fish and oysters; FM: fish and macroalgae

\begin{tabular}{|c|c|c|c|c|c|}
\hline $\begin{array}{l}\text { Functional } \\
\text { group }\end{array}$ & Treatment & $\begin{array}{c}\text { Average } \\
\text { biomass } \\
\left(\mathrm{g} \mathrm{m}^{-2}\right)\end{array}$ & $\mathrm{P}: \mathrm{B}$ & $\mathrm{C}: \mathrm{B}$ & $\begin{array}{l}\text { Total accu- } \\
\text { mulated biomass } \\
\left(\mathrm{g} \mathrm{m}^{-2} 8 \mathrm{mo}^{-1}\right)\end{array}$ \\
\hline \multirow{3}{*}{ Meagre } & FOM & 1116.875 & 1.011 & 2.989 & 1037.955 \\
\hline & $\mathrm{FO}$ & 1140.998 & 1.040 & 2.967 & 1085.117 \\
\hline & FM & 908.662 & 0.721 & 3.010 & 625.431 \\
\hline \multirow[t]{3}{*}{ Seabream } & FOM & 204.624 & 1.294 & 3.181 & 232.350 \\
\hline & $\mathrm{FO}$ & 182.847 & 1.150 & 3.295 & 189.121 \\
\hline & FM & 192.489 & 1.216 & 3.222 & 208.118 \\
\hline \multirow[t]{3}{*}{ Mullet } & FOM & 186.447 & 0.578 & & 107.679 \\
\hline & $\mathrm{FO}$ & 156.459 & 0.305 & & 47.703 \\
\hline & $\mathrm{FM}$ & 175.224 & 0.487 & & 85.232 \\
\hline \multirow[t]{2}{*}{ Oyster } & FOM & 217.576 & 3.333 & & 260.890 \\
\hline & $\mathrm{FO}$ & 131.064 & 1.800 & & 200.833 \\
\hline \multirow{3}{*}{$\begin{array}{l}\text { Macroalgae } \\
\text { and periphyton }\end{array}$} & FOM & 45.019 & 27.972 & & 331.3 \\
\hline & $\mathrm{FO}$ & 24.702 & 27.972 & & 321.5 \\
\hline & FM & 43.015 & 27.972 & & 294.0 \\
\hline \multirow[t]{3}{*}{ Phytoplankton } & FOM & 12.405 & 250 & & \\
\hline & $\mathrm{FO}$ & 15.125 & 250 & & \\
\hline & FM & 9.988 & 250 & & \\
\hline
\end{tabular}


evaluated. The daily biomass and production were then calculated, as well as the average biomass and $\mathrm{P}: \mathrm{B}$ ratios (Table $\mathrm{S} 1$ ). The parameter estimations that were included in the Ecopath models are summarized in Table 4.

The initial biomass was similar for both treatments $\left(18 \mathrm{~g} \mathrm{~m}^{-2}\right.$ ) but the final biomass in the FO treatment was lower when compared to FOM (Table 2) because mortality was higher. In both treatments, there was a high increase in mortality when temperature rose above $26^{\circ} \mathrm{C}$ (Cunha et al. 2019a). The final survival rates were around 19 and $16 \%$ in the FOM and FO treatments, respectively.

\subsubsection{Macroinvertebrates and zooplankton}

Macroinvertebrate biomass was estimated based on data from sampling carried out previously (May 2011 to September 2012) in the same ponds and similar experiments (Machado et al. 2014). The invertebrate fauna was divided into 4 groups: Crustacea, Gastropoda, Bivalvia and Annelida (Table 2). These were the same groups considered previously in the Ria Formosa (RF) model in Gamito \& Erzini (2005) and are used in the present paper for comparison. The average density of each taxon (number of individuals $\mathrm{m}^{-2}$ ) was estimated and converted into biomass $\left(\mathrm{g} \mathrm{m}^{-2}\right)$. For biomass estimations, the average weights of each taxon and their P:B ratios were taken from research carried out in RF (Sprung 1994, Gamito 1997), and conversion factors from dry weight (DW) into WW were from Ruhmor et al. (1987) and Ricciardi \& Bourget (1998). Machado et al. (2014) did not sample the invertebrates associated to macroalgae, usually amphipods and isopods grazing on periphyton, but also gastropods such as Peringia ulvae (Winemiller 1996). These organisms were, however, included in our macroinvertebrate functional groups, not only in terms of biomass, by increasing the average biomass of the crustacean and gastropod groups, but also in the diet relationships (Table 3). The same biomasses and P:B ratios were adopted for the 3 treatments, as well as a P:C ratio of 0.20 , as explained in Section 2.2.2 (Table 2).

The diet composition matrix (Table 3 ) for the macroinvertebrates was built based on the feeding relationship knowledge for the most abundant species. The most abundant taxa sampled at the ponds were the bivalves Abra segmentum and A. tenuis, the polychaetes Hediste diversicolor and Capitella sp. and the gastropod P. ulvae (Machado et al. 2014). The bivalves Abra spp. are deposit feeders (Yonge
1949), but are considered to also be suspension feeders depending on food availability (e.g. Sprung 1994, Gamito 2008). Many deposit-feeding bivalves can switch back and forth from suspension feeding and deposit feeding, depending upon the conditions of the environment (Dame 2012). H. diversicolor is omnivorous, exhibiting a diversity of feeding modes: carnivory, scavenging, filter feeding and deposit feeding (Barnes 1994). Capitella sp. is a non-selective subsurface deposit feeder (Fauchald \& Jumars 1979), feeding on micro-organisms, phytoplankton and detritus. $P$. ulvae was considered to be a surface deposit feeder, feeding primarily on microphytobenthos (mainly benthic diatoms) (Barnes 2003), and a grazer, feeding on periphyton associated with seagrasses and macroalgae (Araújo et al. 2015 and references therein). These feeding relationships were included in the diet composition matrix (Table 3).

Zooplankton biomass was estimated from average counts on species densities from previous trials in similar cultured conditions. For each species, an average volume and weight was calculated, based on Wiebe et al. (1975), Uye (1982), Halliday (2001) and Kiørboe (2013). A total biomass of $0.918 \mathrm{~g} \mathrm{~m}^{-2}$ was estimated. Since there were no production estimates, a P:B ratio of $60\left(8 \mathrm{mo}^{-1}\right)$ was adopted, based on Heip et al. (1995) and on preliminary simulations. A P:B range of 45-150 $\mathrm{yr}^{-1}$, for estuarine autochthonous zooplankton, was reported by Heip et al. (1995).

\subsubsection{Primary producers: macroalgae and periphyton; phytoplankton}

Periphyton was aggregated with macroalgae in a functional group, since it covered most of the macroalgae tally and it was difficult to estimate their biomass per se. Polynomial equation models were adjusted to the biomass of macroalgae and periphyton harvested during the experiments, to estimate their average daily biomass (Table S4). According to field worker observations, around $20 \%$ of the macroalgae remained in the ponds after harvesting. Likewise, all average estimated biomasses integrated in the models were increased by $20 \%$. In FO ponds, although the total amount of macroalgae was similar to the amount harvested in the other experiments, the average biomass was lower than in the other 2 treatments (Table 4), due to frequent harvesting.

Evaluation of Ulva production was carried out in treatments FOM and FM. This was done based on the information from 6 rafts of $1 \mathrm{~m}^{2}$ each (Favot et al. 
2019), giving an average P:B ratio of 27.972. This value was included in all models.

Phytoplankton biomass was estimated based on the monthly concentration of chlorophyll $a(\mathrm{chl} a)$ in the ponds (Cunha at al. 2019a,b). The average concentration of chl $a$ in the ponds varied between 13 and $20 \mu \mathrm{g} \mathrm{l}^{-1}$, or between 20 and $30 \mathrm{mg} \mathrm{m}^{-2}$, taking into consideration that each pond has an area of $500 \mathrm{~m}^{2}$ and a depth of $1.5 \mathrm{~m}$. A conversion factor of 500 was used to convert phytoplankton chl a to phytoplankton biomass (WW) (Strickland 1966, Link et al. 2006, Kasprzak et al. 2008), which resulted in phytoplankton biomass varying between 10 and $15 \mathrm{~g} \mathrm{~m}^{-2}$ (Table 4).

A phytoplankton P:B ratio of 250 was estimated using production values obtained in the same ponds in 2011 and 2012. An average daily period of $7 \mathrm{~h}$ of optimal light was assumed for the modeling period, since in the Algarve there are a total of 9.75 daylight hours per day from the end of March until the end of November (www.temperatureweather.com/ mediterr/tempo/pt-tempo-na-portugal-faro.htm).

\subsubsection{Formulated feed and detritus}

The total amount of feed distributed to each pond was about $1180 \mathrm{~kg}$ DW during the production cycle. DW was converted to WW based on the factor of 1:2 obtained in laboratory observations. The total amount of wet feed was then $2360 \mathrm{~kg}$ pond ${ }^{-1}$, which corresponds to a total of $4720 \mathrm{~g} \mathrm{~m}^{-2} 8 \mathrm{mo}^{-1}$ (Table 2), and was included in the models as detritus import. From the tendency function adjusted to the monthly amount of food given per pond (Table S3), an average daily input of food was estimated as $18.834 \mathrm{~g}$ $\mathrm{m}^{-2}$. Since no information on the biomass of natural detritus was available, a value of $19 \mathrm{~g} \mathrm{~m}^{-2}$ similar to the estimated biomass of artificial feed was assumed (Table 2). The detritus biomass has no implications for model balancing.

\subsection{Model simulations and interpretation}

The results of the simulations were compared to previous results obtained for a model developed for a naturalized earthen pond at RF due to the high rate of water renewal and no artificial feed (Gamito \& Erzini 2005). The 2 sets of models were compared to assess the effects of artificialization in the IMTA ponds. Since the units used in the older model were in DW, a rough conversion factor of 1:0.27 was used to convert the old DW model into WW, the same con- version factor adopted for fish in Gamito \& Erzini (2005). Except for the ratios, the system global statistics were multiplied by 0.75 , since the time of 1 production cycle was $8 \mathrm{mo}$, instead of a year as used in Gamito \& Erzini (2005).

Some EwE statistics were selected to compare the results of the different models, namely total system throughput, net system production, average path length, connectance index, system omnivory index, ascendency, and Finn's cycling index. Total system throughput is the sum of all flows in a system, and includes the total consumption, total export, total respiration and total flows to detritus (Christensen et al. 2005). This parameter represents the size of the system in terms of flow (Ulanowicz 1986) and therefore is important for comparisons of networks (Christensen et al. 2005). Net system production is the difference between total primary production and total respiration and will be large in immature systems and close to zero in mature ones (Christensen 1995, Christensen et al. 2005). The total primary production:total respiration ratio approaches 1 in mature systems, when the energy that is fixed is balanced by the cost of maintenance (Christensen et al. 2005). Average path length, connectance index, and system omnivory index are related to food web organization. The connectance index is the ratio of the number of actual links to the number of possible links (Krebs 2013). Higher ratios would point to a more complex web. Since this ratio is strongly affected by the level of taxonomic detail used to represent prey groups, it is recommended to use the system omnivory index to characterize the web-like features (Christensen et al. 2005). This index is a measure of how the feeding interactions are distributed between trophic levels, being defined as the average omnivory index of all consumers weighted by the logarithm of each consumer's food intake (Christensen et al. 2005).

Ascendency, derived from information theory, is a measure of the average mutual information in a system, scaled by system throughput (Ulanowicz \& Norden 1990, Christensen et al. 2005). A rise in ascendency would represent an increase in system size or organization (Jørgensen 2002). Finn's cycling index, developed by Finn (1976), and expressed as a percentage, represents the fraction of an ecosystem's throughput that is recycled (Christensen et al. 2005).

\section{RESULTS}

The final estimates of the 3 IMTA models are given in Table 5. Fish species presented lower C:B ratios 
compared with the invertebrates, since their growth rates and P:B ratios were also lower. The groups with higher P:B ratios, such as invertebrates and zooplankton, had a higher turnover rate and higher $\mathrm{C}: \mathrm{B}$ ratios.

The produced fish species had EE values close to 1, since all biomass produced was accumulating in the ponds until final harvesting (Table 5). For groups with considerable predation, this parameter approaches 1, while low values mean that most of the consumption is not consumed or explained by the model (Christensen et al. 2005). Oysters had higher $\mathrm{EE}$ in the FO treatment where the growth of macroalgae was controlled. Crustaceans, such as small amphipods and isopods, that grew preferentially close to the surfaces of macroalgae and where the periphyton was abundant, were consumed to almost the limit in the FOM treatment, denoted by an EE close to 1. The EE of gastropods, although lower, showed a trend similar to that of the crustaceans. Bivalves and polychaetes had relatively low EEs. In fact, in the models, few predators preyed upon these groups. Zooplankton EE was close to 1 in the FOM treatment due to the higher mullet biomass, defined as its sole predator in the models. Even though they were consumed by few groups, macroalgae and periphyton were regularly harvested, which increased the $\mathrm{EE}$, and this was more evident in the treatment FO where this practice was regular. In the FOM treatment, the phytoplankton EE was close to 1, suggesting that oysters were consuming most of the phytoplankton production. The lower phytoplankton EE values in the FM and FO treatments $(0.13$ and 0.31) indicates that most of the phytoplankton pro- duction was not being consumed despite the presence of oysters in the FO treatment. In the FOM and FO treatments, almost all formulated feed was consumed. In the FM treatment, since meagre did not grow well, the total amount of fish biomass was not enough to consume all the distributed feed.

The estimated P:C ratios of meagre and seabream varied between 0.24 and 0.41 (Table 5). Higher ratios indicate lower consumption for the same production, or a higher efficiency in converting feed into accumulated biomass. In the FM treatment, meagre grew less but had the same amount of available food and a similar $\mathrm{C}: \mathrm{B}$ ratio. The $\mathrm{P}: \mathrm{C}$ ratio of meagre decreased to 0.24 in that treatment due to the significant decrease in the final production of this species.

In the IMTA experimental ponds, the trophic web was very simplified since the potential top predators were fed artificial pellets (Fig. 1). The highest trophic levels were observed in the mullets and annelids. Both groups fed on several items, compared with meagre and bream, which only ate artificial feed. In the RF water pond model (Gamito \& Erzini 2005), the trophic food web had higher diversity and a higher number of connections, when compared to our IMTA models. The functional groups were spread over several trophic levels, from the lowest level, that included primary producers and detritus, to the higher trophic levels of 3.4 attributed to the pelagic-benthic fish feeders, and 3.2 and 3.3 attributed to Sparus aurata and Spondyliosoma cantharus, respectively (Fig. 2). In the IMTA ponds, the biomass accumulated in the produced species (the 3 fish species and the oysters), while in the natural system, it spread over the

Table 5. Basic estimates of integrated multi-trophic aquaculture (IMTA) Ecopath models, in bold. Non-bold numbers are input values. FOM: fish, oysters and macroalgae; FO: fish and oysters; FM: fish and macroalgae

\begin{tabular}{|c|c|c|c|c|c|c|c|c|c|c|}
\hline \multirow[t]{2}{*}{$\begin{array}{l}\text { Functional } \\
\text { group }\end{array}$} & \multirow[t]{2}{*}{$\begin{array}{c}\text { Trophic } \\
\text { level }\end{array}$} & \multicolumn{3}{|c|}{$\begin{array}{c}\text { - Consumption:biomass - } \\
\left(8 \mathrm{mo}^{-1}\right)\end{array}$} & \multicolumn{3}{|c|}{$\begin{array}{c}\text { Ecotrophic }- \\
\text { efficiency }\end{array}$} & \multicolumn{3}{|c|}{$\begin{array}{l}\text { Production:consumption } \\
\qquad\left(8 \mathrm{mo}^{-1}\right)\end{array}$} \\
\hline & & FOM & $\mathrm{FO}$ & FM & FOM & FO & FM & FOM & $\mathrm{FO}$ & FM \\
\hline Meagre & 2 & 2.989 & 2.967 & 3.010 & 0.919 & 0.914 & 0.955 & 0.338 & 0.351 & 0.240 \\
\hline Seabream & 2.005 & 3.181 & 3.295 & 3.222 & 0.881 & 0.899 & 0.889 & 0.407 & 0.349 & 0.377 \\
\hline Mullet & 2.145 & 2.890 & 1.525 & 2.435 & 0.999 & 1.000 & 0.999 & 0.2 & 0.2 & 0.2 \\
\hline Oyster & 2 & 16.645 & 9.000 & & 0.358 & 0.851 & & 0.2 & 0.2 & \\
\hline Crustacea & 2 & 24.650 & 24.650 & 24.650 & 0.958 & 0.670 & 0.847 & 0.2 & 0.2 & 0.2 \\
\hline Gastropoda & 2 & 9.050 & 9.050 & 9.050 & 0.876 & 0.387 & 0.693 & 0.2 & 0.2 & 0.2 \\
\hline Bivalvia & 2 & 13.550 & 13.550 & 13.550 & 0.405 & 0.305 & 0.368 & 0.2 & 0.2 & 0.2 \\
\hline Annelida & 2.041 & 26.20 & 26.20 & 26.20 & 0.140 & 0.118 & 0.131 & 0.2 & 0.2 & 0.2 \\
\hline Zooplankton & 23 & 300.00 & 300.00 & 300.00 & 0.979 & 0.433 & 0.775 & 0.2 & 0.2 & 0.2 \\
\hline Macroalgae and periphyton & 1 & & & & 0.445 & 0.628 & 0.402 & & & \\
\hline Phytoplankton & 1 & & & & 0.912 & 0.306 & 0.133 & & & \\
\hline Feed & 1 & & & & 0.974 & 0.912 & 0.744 & & & \\
\hline Detritus & 1 & & & & 0.332 & 0.177 & 0.156 & & & \\
\hline
\end{tabular}


5

4

3

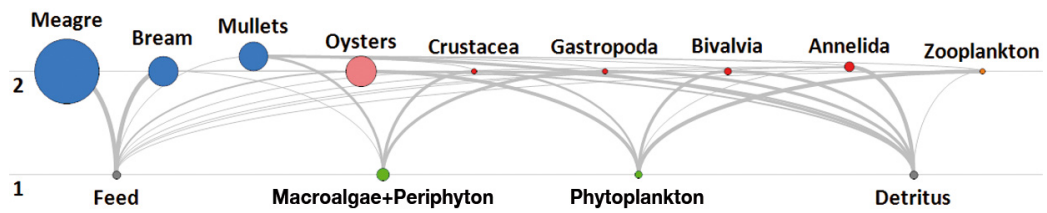

Fig. 1. Food web structure in the fish, oysters and macroalgae (FOM) treatment model. The 3D volume represented by each circle is proportional to the average biomass of the functional group. Numbers = trophic levels. Blue: fish; pink: oysters; red: macroinvertebrates; orange: zooplankton; green: primary producers; grey: detritus groups

5

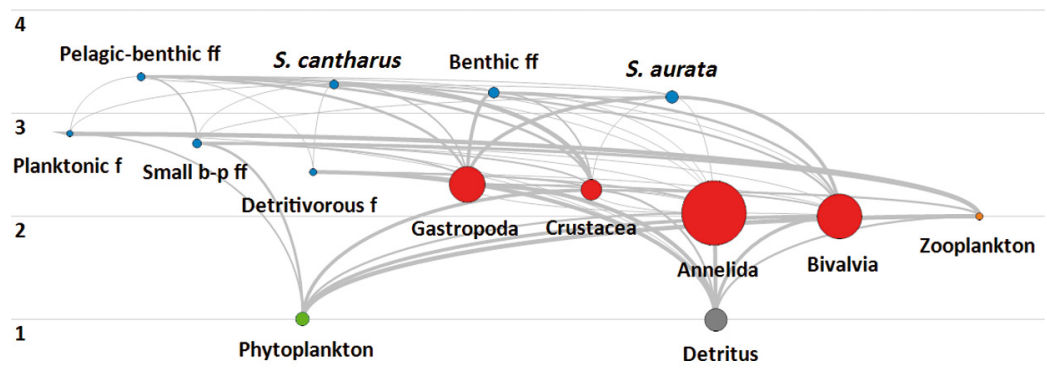

Fig. 2. Food web structure at a Ria Formosa water pond, with comparable environmental characteristics to the ones found at the lagoon tidal channels (based on Gamito \& Erzini 2005). Functional fish groups: pelagic and benthic feeders, Spondyliosoma cantharus, benthic invertebrate feeders, Sparus aurata, planktonic feeders, small pelagic-benthic feeders, detritivorous fish. Macroinvertebrate groups: Crustacea, Gastropoda, Bivalvia and Annelida. The 3D volume represented by each circle is proportional to the average biomass of the functional group. Numbers = trophic levels. Colours as in Fig. 1. ff: feeder fish; f: fish; b-p ff: pelagic-benthic feeder fish

different trophic levels, with high expression on the primary consumers, the benthic invertebrates.

Total system throughput, which represents the size of the system in terms of flow (Ulanowicz 1986), was much higher in the IMTA systems with oysters (Table 6). The total amount of energy throughput in the 4 models could be compared after converting DW into WW in the RF model. In that natural system, the total system throughput was about 15 to 17 times lower than in the IMTA models. Net system production corresponds to the difference between total primary production and total respiration. Compared to the natural system (RF), the FO and FM models in the present study showed higher net system production values, by more than 580 and 430 times respectively, while in the FOM model it was much lower than in
FO and FM, but still 142 times higher than the RF model. Total biomass (excluding both detritus groups) was much higher in the IMTA systems, 57 and 53 times more for the 2 treatments that included oysters (FOM and FO) and 43 times higher in the FM treatment, when compared with the RF model. The total primary production:total respiration ratio was higher than in the RF model, varying from 1.51 to 1.58 in the FM and FO models, while in RF it was 1.01. In the FOM model, this ratio was 1.10, which approaches the value observed in the RF model. Moreover, in the 3 IMTA ponds, the total number of pathways and the average trophic length were much lower, which confirms a chain food structure, compared to the weblike structure of the RF, which had $>1300$ connections and a higher average path length. All other indicators included in Table 6 point to lower values in the IMTA models when compared with the RF model, except for ascendency, which was higher than in the RF model. Ascendency was around $50 \%$ in the 3 IMTA models and $24 \%$ in the RF model.

The connectance index was around 0.3 in the IMTA ponds and 0.4 in the RF model, indicating a less complex web in the IMTA system. Since this ratio is strongly affected by the level of taxonomic detail used to represent prey groups (Christensen et al. 2005), the system omnivory index was also used to characterize the web-like features. The system omnivory index varied between 0.019 and 0.025 in the IMTA ponds and was 0.092 in the RF model. Both indexes pointed to a more complex food web in RF then in the IMTA ponds. Finn's cycling index, which represents the fraction of an ecosystem's throughput that is recycled (Christensen et al. 2005), varied between 2.5 and $4.5 \%$ in the IMTA ponds, and was $30 \%$ of total throughput in RF.

The Ecopath pedigree is an index that evaluates the quality and uncertainty of the input and output parameters. All IMTA models had high data quality, since most of the parameters are from observed real data, which is reflected in a high pedigree index of 0.65 for the FOM and FO models (Table 6). In the FM 
Table 6. Summary statistics for the 4 Ecopath models. FOM: fish, oysters and macroalgae; FO: fish and oysters; FM: fish and macroalgae; RF: Ria Formosa natural pond (based on the model in Gamito \& Erzini 2005)

\begin{tabular}{|lcccc|}
\hline & FOM & FO & FM & RF \\
\hline Total system throughput $\left(\mathrm{g} \mathrm{m}^{-2} 8 \mathrm{mo}^{-1}\right)$ & 25845 & 24257 & 22601 & 1553 \\
Net system production $\left(\mathrm{g} \mathrm{m}^{-2} 8 \mathrm{mo}^{-1}\right)$ & 406 & 1660 & 1256 & 2.86 \\
Total biomass (excluding detritus) $\left(\mathrm{g} \mathrm{m}^{-2} 8 \mathrm{mo}^{-1}\right)$ & 1827 & 1697 & 1374 & 31.88 \\
Total primary production:total respiration ratio & 1.103 & 1.582 & 1.511 & 1.009 \\
Total number of pathways & 18 & 18 & 17 & 1308 \\
Average path length & 2.611 & 2.611 & 2.647 & 5.964 \\
Connectance index & 0.284 & 0.283 & 0.310 & 0.414 \\
System omnivory index & 0.021 & 0.019 & 0.025 & 0.092 \\
Ascendency (\%) & 48.39 & 49.20 & 50.36 & 23.76 \\
Finn's cycling index (\% of total throughput) & 4.521 & 2.588 & 2.483 & 30.09 \\
Ecopath pedigree & 0.650 & 0.650 & 0.611 & \\
\hline
\end{tabular}

model, the pedigree index was slightly lower. In this model, one of the groups with precise estimates, the oysters, was not included, which consequently increased the effect of the groups with approximate estimates.

\section{DISCUSSION}

The 3 IMTA treatments used a multi-trophic production approach by introducing different trophic groups into the same ponds in order to recycle the introduced energy in the system. Wild meagre Argyrosomus regius usually feed on other fish such as atherinids, mugilids and clupeids (Costa 1991), having an estimated trophic level of 4.29 (Froese \& Pauly 2019). White seabream Diplodus sargus has a similar feeding behavior to Sparus aurata, being considered an omnivore that feeds on algae, shellfish and other benthic invertebrates, with an estimated trophic level varying between 3.24 and 3.38 (Rosecchi 1987, Sala \& Ballesteros 1997, Froese \& Pauly 2019). These 2 fish species in the IMTA pond model reached a trophic level of just 2 (Table 5), since they fed mostly on artificial food. Nevertheless, the estimated P:C ratio for meagre and bream was around 0.3 , which indicates they were consuming high-quality food. These fish ate daily lower amounts of food biomass than they would likely need to consume in the wild.

In these ponds, the macroalgae and oysters were not consumed by any trophic group, although they may also have been a profit source for the aquaculture system. In a natural system, other organisms would have consumed those groups. Furthermore, most of the cultivated fish species had high-quality food permanently available, which was easily cap- tured and consumed. Consequently, none of these species consumed other fish or macroinvertebrates. The trophic web was therefore very simplified, of a linear type, with only 17 to 18 pathways and an average path length of 2.6, when compared with the natural RF pond, which has an estimated number of pathways of about 1300 and an average path length of almost 6 (Table 6). Other organisms, such as the macroalgae, could be an important resource of the multi-trophic ponds and are an essential substrate for periphyton and small invertebrate fauna. Periphyton and associated fauna can be an important feeding source for fish such as mullets (Jana et al. 2004). The regular cleaning up of macroalgae may have a negative impact on these invertebrates and possibly on fish that prey upon them. Furthermore, macroalgae also help to absorb and reduce the excess nutrients in the ponds, and to oxygenate the water.

The ecotrophic efficiency (EE) values of the aquacultured species were close to 1 , indicating that the ponds were close to the maximum capacity. The carrying capacity of the system was already artificially raised by the addition of formulated feed and by increasing water renewal rates and aeration periods. Since the phytoplankton was not completely consumed, the system could possibly have supported more oysters, but that could cause a shortage of food for zooplankton. In the ponds where the macroalgae were not present in high abundances (FO model), there was lower competition for nutrients and the phytoplankton abundance increased, which may explain the lower EE in comparison to the FOM model. In addition, the biomass of oysters was higher in the FOM model. It is important to note, however, the very low EE of the phytoplankton group in the FM model, which indicates that the majority of this production was not being used by the system. The detritus group also showed low EE values, which indicates that there were not enough organisms consuming it and therefore it accumulated in the ponds. In fact, once a week, the floor of the ponds was purged, to allow the release of the accumulated organic matter to the settling pond.

The net system production is usually high in early developmental ecosystem stages and close to zero in mature ones (Christensen 1995). According to this author, systems with large imports may have a negative system production. However, in our IMTA ponds, 
the large quantities of artificial feed imported allowed the development of high biomasses of all trophic groups, including the primary producers, mainly of phytoplankton, increasing the difference between total primary production and total respiration, and consequently of the net system production. In addition, the ratio between these 2 parameters (total primary production:total respiration) was $>1$, reflecting the immature nature of these systems compared with the RF model, or the degree of their artificialization. In the RF pond, this ratio approached 1, which indicates a 'mature' system, where the energy that is fixed is approximately balanced by the cost of maintenance (Christensen et al. 2005, Gamito \& Erzini 2005). In the FOM model, the ratio was lower than in the other 2 IMTA models, approaching 1, which can indicate an optimization of the resource utilization in this treatment. Due to the large import of energy, total biomass (excluding both detritus groups) was much higher in the artificialized systems, when compared with the RF model.

The higher value of the connectance index in the RF model confirms a more mature system with a web-like chain, compared to more simple and linear trophic relationships among the functional groups in the IMTA ponds. The food chain is expected to change from linear to web-like as the system matures (Odum 1969, 2004, Christensen 1995, ManickchandHeileman et al. 2004). The system omnivory index confirms these conclusions. This index has larger values when the consumers feed on many trophic levels (Christensen et al. 2005).

Ascendency was higher in the 3 IMTA models, almost double the value observed in the RF model. Ulanowicz (1980) defines ascendency as an index that quantifies both the level of system activity and the degree of organization with which material is being processed in ecosystems. A rise in ascendency corresponds to an increase in system size or organization (Jørgensen 2002). However, more eutrophicated systems, such as the IMTA ponds, may also show higher ascendency values, due to an overall increase of activity of the system that compensates a decrease in its developmental stage (Ulanowicz 2000). Finn's cycling index was much higher in the RF natural system, indicating a higher resilience to external disturbances. This index indicates the fraction of an ecosystem's throughput that is recycled and is strongly correlated with system maturity, resilience and stability (Christensen et al. 2005). Therefore, the low values of Finn's cycling index, of about 2.5 to $4.5 \%$ of total throughput, in the 3 IMTA models, compared with the $30 \%$ observed in the RF model, indicate very low organic matter recycling and consequently low ecosystem maturity and low resilience and stability.

Most of the data introduced in the models were of high quality. There were precise estimates of biomass and $\mathrm{P}: \mathrm{B}$ ratios of most of the functional groups, as well as of the diet composition. The pedigree index-an index that evaluates the quality and uncertainty of the input and output parameterswas 0.65 , a value comparable to other published models. For example, Deng et al. (2015) estimated a pedigree of 0.61 , and Morissette et al. (2006) estimated an average value of 0.651 , values that both groups of authors considered higher than the average. In fact, Morissette (2007), based on 50 ecosystem models, estimated an average pedigree of 0.44 .

The 3 IMTA models expressed the ecosystem state differences of a multi-trophic semi-intensive system from a naturalized ecosystem, due to the high introduction of energy through the artificial feed added and increased aeration necessary to sustain the elevated biomass of the produced organisms. The FM model had only 12 functional groups compared with the 13 groups included in the other IMTA models, since no oysters were produced. In this treatment, the total biomass throughput was lower, although the same amount of formulated feed was given. Some resources were not used so intensively, notably the phytoplankton, which is reflected by the lower EE of this group (Table 5). In addition, phytoplankton concentration was lowest in this treatment.

EwE has been used to describe some aquaculture systems such as the effect of cage aquaculture in food web structure and fisheries (Bayle-Sempere et al. 2013), the carrying capacity of shellfish culture (e.g. Byron et al. 2011) or other IMTA aquaculture systems such as the agro-ecological aquaculture integration in a river delta in Vietnam (Phong et al. 2010) or in a mangrove polyculture system of Pearl River Delta, China (Xu et al. 2011). In the present IMTA experiments, it was possible to build EwE ecosystem models, with information of high quality, mostly derived from direct observations and sampling in the experimental ponds. The comparisons of the simulation from the IMTA models with the simulations of a naturalized pond in the same lagoon system, the RF, shows the effects of making the system more artificial and of intensification of production. A great quantity of energy is added to the system, which allows a high production of fish and bivalve biomass. The ecosystem is extremely simplified, shifting from a food web to a food chain, and the recycling of organic matter is low. The high concentra- 
tion of biomass and low recycling demands high rates of water renewal and aeration to maintain water quality.

Among the 3 treatments, the addition of oysters in the multi-trophic system was an advantage, since they consumed the high-density phytoplankton available. Furthermore, the maintenance of high controlled densities of macroalgae and periphyton was also an advantage, as it increased nutrient absorption but also created habitat for macroinvertebrates which help to recycle organic matter and transfer energy to higher trophic levels. In the FOM treatment, with oysters and macroalgae, some ecosystem attributes approached the values of the naturalized RF model, suggesting a possible way towards more sustainable aquaculture.

Acknowledgements. The results were obtained within the framework of the ERA-Net COFASP project IMTA-Effect managed in Portugal by Fundacão para a Ciência e Tecnologia (COFASP/0003/2015) with a follow-up by the Interreg Atlantic Area project INTEGRATE (EAPA_232/2016). H.Q.F. was funded by project DIVERSIAQUA (Mar2020 16-0201-FMP-0066), and S.G. by projects UID/Multi/04326/2019 and UID/Multi/04326/2020. We are grateful to the anonymous reviewers for their constructive comments and suggestions.

\section{LITERATURE CITED}

Anras L, Boglione C, Cataudella S, Dinis MT and others (2010) The current status of extensive and semi-intensive aquaculture practices in Southern Europe. Aquacult Eur 35:12-16

Araújo CVM, Moreira-Santos M, Patricio J, Martins I and others (2015) Feeding niche preference of the mudsnail Peringia ulvae. Mar Freshw Res 66:573-581

Arreguín-Sanchez F, Valero-Pacheco E, Chávez EA (1993) A trophic box model of the coastal fish communities of the southwestern Gulf of Mexico. ICLARM Conf Proc 26: 197-205

Azim ME, Verdegem MCJ, van Dam AA, Beveridge MCM (2005) Periphyton: ecology, exploitation, and management. CAB International, Wallingford

Barnes RSK (1994) The brackish-water fauna of northwestern Europe. Cambridge University Press, Cambridge

Barnes RSK (2003) Feeding rates of continually submerged Hydrobia ulvae vary during the daylight hours. J Mar Biol Assoc UK 83:1273-1275

Barrington K, Chopin T, Robinson S (2009) Integrated multitrophic aquaculture (IMTA) in marine temperate waters. In: Soto D (ed) Integrated mariculture: a global review. FAO Fish Aquacult Tech Pap 529:7-46

Bayle-Sempere JT, Arreguin-Sanchez F, Sanchez-Jerez P, Salcido-Guevara LA, Fernandez-Jover D, Zetina-Rejon MJ (2013) Trophic structure and energy fluxes around a Mediterranean fish farm. Ecol Modell 248:135-147

Bostock J, McAndrew B, Richards R, Jauncey K and others (2010) Aquaculture: global status and trends. Philos Trans R Soc B 365:2897-2912

Brando VE, Ceccarelli R, Libralato S, Ravagnan G (2004) Assessment of environmental management effects in a shallow water basin using mass-balance models. Ecol Modell 172:213-232

Brito GV (2018) Fatty acids as dietary tracers in integrated production of fish, oysters and macroalgae in earthen ponds. Master's thesis, Universidade do Algarve, Faro

* Byron C, Link J, Costa-Pierce B, Bengtson D (2011) Modeling ecological carrying capacity of shellfish aquaculture in highly flushed temperate lagoons. Aquaculture 314: 87-99

Chopin T (2012) Aquaculture, integrated multi-trophic (IMTA). In: Meyers RA (ed) Encyclopaedia of sustainability science and technology. Springer, New York, NY, p 542-564

Chopin T, Robinson SMC, Troell M, Neori A, Buschmann AH, Fang J (2008) Multi-trophic integration for sustainable marine aquaculture. In: Jørgensen SE, Fath BD (eds) The encyclopedia of ecology: ecological engineering, Vol 3. Elsevier, Oxford, p 2463-2475

Christensen V (1995) Ecosystem maturity-towards quantification. Ecol Modell 77:3-32

Christensen V (1998) Fishery-induced changes in a marine ecosystem: insight from models of the Gulf of Thailand. J Fish Biol 53:128-142

Christensen V (2009) Ecopath with Ecosim: linking fisheries with ecology. In: Jørgensen SE, Chon TS, Recknagel F (eds) Handbook of ecological modelling and informatics. WIT Press, Ashurst, p 55-70

Christensen V, Walters CJ, Pauly D (2005) Ecopath with Ecosim: a user's guide. Fisheries Centre, University of British Columbia, Vancouver

Colléter M, Valls A, Guitton J, Gascuel D, Pauly P, Christensen V (2015) Global overview of the applications of the Ecopath with Ecosim modelling approach using the EcoBase models repository. Ecol Modell 302:42-53

Costa F (1991) Atlante dei pesci dei mari italiani. Gruppo Ugo Mursia Editore, Milan

* Cunha ME, Quental-Ferreira H, Parejo A, Gamito S and others (2019a) Understanding the individual role of fish, oyster, phytoplankton and macroalgae in the ecology of integrated production in earthen ponds. Aquaculture 512:734297

Cunha ME, Quental-Ferreira H, Parejo A, Gamito S and others (2019b) Methodology for assessing the individual role of fish, oyster, phytoplankton and macroalgae in the ecology of integrated production in earthen ponds. MethodsX 6:2570-2576

Dame RF (2012) Ecology of marine bivalves: an ecosystem approach, 2nd edn. CRC Press, Boca Raton, FL

* Deng L, Liu S, Dong S, An N, Zhao H, Liu Q (2015) Application of Ecopath model on trophic interactions and energy flows of impounded Manwan reservoir ecosystem in Lancang River, southwest China. J Freshw Ecol 30:281-297

Fauchald J, Jumars PA (1979) The diet of worms: a study of polychaete feeding guilds. Oceanogr Mar Biol Annu Rev 17:193-284

Favot G, Engelen AE, Cunha ME, Serrão MEA (2019) Identification of Ulva sp. grown in multitrophic aquaculture systems. J Aquacult Fish 3:024

Ferreira H, Ramalho Ribeiro A, Dias J, Yufera M and others (2010) Sustainable semi-intensive polyculture of seabream and sole in earthen ponds. Aquacult Eur 35(3):17-21

Finn JT (1976) Measures of ecosystem structure and function derived from analysis of flows. J Theor Biol 56:363-380

Froese R, Pauly D (eds) (2019) FishBase. www.fishbase.org (accessed Nov 2019) 
Gamito S (1997) Sustainable management of a coastal lagoonal system (Ria Formosa, Portugal): an ecological model for extensive aquaculture. Int J Salt Lake Res 6: $145-173$

Gamito S (2008) Three main stressors acting on the Ria Formosa lagoonal system (Southern Portugal): physical stress, organic matter pollution and the land-ocean gradient. Estuar Coast Shelf Sci 77:710-720

Gamito S, Erzini K (2005) Trophic food web and ecosystem attributes of a water reservoir of the Ria Formosa (south Portugal). Ecol Modell 181:509-520

Granada L, Sousa N, Lopes S, Lemos MFL (2016) Is integrated multitrophic aquaculture the solution to the sectors' major challenges? A review. Rev Aquacult 8:283-300

Halliday NC (2001) A comparison of morphometric and geometric methods for the estimation of individual zooplankton volumes. Sarsia 86:101-105

Heip CHR, Goosen NK, Herman PMJ, Kromkamp J, Middelburg JJ, Soetaert K (1995) Production and consumption of biological particles in temperate tidal estuaries. Oceanogr Mar Biol Annu Rev 33:1-149

* Heymans JJ, Coll M, Link JS, Mackinson S, Steenbeek J, Walters C, Christensen V (2016) Best practice in Ecopath with Ecosim food-web models for ecosystem-based management. Ecol Modell 331:173-184

Hyder K, Rossberg AG, Allen JI, Austen MC and others (2015) Making modelling count-increasing the contribution of shelf-seas community and ecosystem models to policy development and management. Mar Policy 61: 291-302

Jana SN, Garg SK, Patra BC (2004) Effect of periphyton on growth performance of grey mullet, Mugil cephalus (Linn.), in inland saline groundwater ponds. J Appl Ichthyol 20:110-117

Jørgensen SE (2002) Integration of ecosystem theories: a pattern, 3rd edn. Kluwer, Dordrecht

Kasprzak P, Padisak J, Koschel R, Krienitz L, Gervais F (2008) Chlorophyll a concentration across a trophic gradient of lakes: an estimator of phytoplankton biomass? Limnologica 38:327-338

Kiørboe T (2013) Zooplankton body composition. Limnol Oceanogr 58:1843-1850

Krebs CJ (2013) Ecology: the experimental analysis of distribution and abundance, 6th edn. Benjamin Cummings, San Francisco, CA

Link JS, Griswold CA, Methratta ET, Gunnard J (eds) (2006) Documentation for the Energy Modeling and Analysis eXercise (EMAX). Ref Doc 06-15. Northeast Fisheries Science Center, NOAA, Woods Hole, MA

Machado M, Mateus M, Quental-Ferreira H, Cunha ME, Cancela da Fonseca L (2014) Efeito da introdução de ostras em piscicultura de tanques de terra na comunidade macrobentónica. In: Pereira SD, Freitas JG, Bergamaschi S, Rodrigues MAC (eds) Formação e ocupação de litorais nas margens do Atlântico-Brasil/Portugal. Corbã Ed., Rio de Janeiro, p 231-243

Manickchand-Heileman S, Mendoza-Hill J, Kong AL, Arocha F (2004) A trophic model for exploring possible ecosystem impacts of fishing in the Gulf of Paria, between Venezuela and Trinidad. Ecol Modell 172:307-322

Morissette L (2007) Complexity, cost and quality of ecosystem models and their impact on resilience: a comparative analysis, with emphasis on marine mammals and the Gulf of St. Lawrence. PhD thesis, University of British Columbia, Vancouver
Morissette L, Hammill MO, Savenkoff C (2006) The trophic role of marine mammals in the northern Gulf of St. Lawrence. Mar Mamm Sci 22:74-103

Nahon S, Brito G, Quental-Ferreira H, Aubin J, Cunha ME (2018) Fatty acids and stable isotopes as tracers of food assimilation in fish-oyster-macroalgae integrated multitrophic aquaculture ponds. In: AQUA 2018 Montpellier Conference, abstract book. World Aquaculture Society, Valley Center, CA, p 536

Odum EP (1969) The strategy of ecosystem development. Science 164:262-270

Odum EP (2004) Fundamentals of ecology, 5th edn. Cole Publishing Company, Belmont, CA

*Phong LT, van Dam AA, Udo HMJ, van Mensvoort MEF, Tri LQ, Steenstra FA, van der Zijpp AJ (2010) An agro-ecological evaluation of aquaculture integration into farming systems of the Mekong Delta. Agric Ecosyst Environ 138:232-241

Ren JS, Stenton-Dozey J, Plew DR, Fang J, Gall M (2012) An ecosystem model for optimising production in integrated multitrophic aquaculture systems. Ecol Modell 246:34-46

Ricciardi A, Bourget E (1998) Weight-to-weight conversion factors for marine benthic macroinvertebrates. Mar Ecol Prog Ser 163:245-251

Kosa J, Lemos MFL, Crespo D, Nunes M and others (2020) Integrated multitrophic aquaculture systems-potential risks for food safety. Trends Food Sci Technol 96: 79-90

Rosecchi E (1987) L'alimentation de Diplodus annularis, Diplodus sargus, Diplodus vulgaris et Sparus aurata (Pisces, Sparidae) dans le Golfe du Lion et les lagunes littorales. Rev Trav Inst Pêches Marit 49:125-141

Ruddle K, Christensen V (1993) Energy flow model of the mulberry dike-carp pond farming system of Zhujiang Delta, Guangdong Province, China. In: Christensen V, Pauly D (eds) Trophic models of aquatic ecosystems. ICLARM Conf Proc 26:48-55

Ruhmor H, Brey T, Ahkar S (1987) A compilation of biometric conversion factors for benthic invertebrates of the Baltic Sea. Balt Mar Biol Publ 9

Sala E, Ballesteros E (1997) Partitioning of space and food resources by three fish of the genus Diplodus (Sparidae) in a Mediterranean rocky infralittoral ecosystem. Mar Ecol Prog Ser 152:273-283

Soto D (ed) (2009) Integrated mariculture: a global review. FAO Fish Aquacult Tech Pap 529. FAO, Rome

Soto D, Aguilar-Manjarrez J, Brugère $C$, Angel D and others (2008) Applying an ecosystem-based approach to aquaculture: principles, scales, and some management measures. In: Soto D, Aguilar-Manjarrez J, Hishamunda N (eds) Building an ecosystem approach to aquaculture. FAO Fish Aquacult Proc 14:15-35

* Sprung M (1994) Macrobenthic secondary production in the intertidal zone of the Ria Formosa-a lagoon in southern Portugal. Estuar Coast Shelf Sci 38:539-558

Steenbeek J, Piroddi C, Coll M, Heymans JJ, Villasante S, Christensen V (eds) (2014) Ecopath 30 Years Conference. Proceedings: extended abstracts. Fish Cent Res Rep, Vol 22, No. 3. University of British Columbia, Vancouver

Strickland JDH (1966) Measuring the production of marine phytoplankton. Bull Fish Res Board Can No. 122

Ulanowicz RE (1980) An hypothesis on the development of natural communities. J Theor Biol 85:223-245

Ulanowicz RE (1986) Growth and development: ecosystem phenomenology. Springer-Verlag, New York, NY 
Ulanowicz RE (2000) Ascendancy: a measure of ecosystem performance. In: Jørgensen SE, Müller F (eds) Handbook of ecosystem theories and management. Lewis Publishers, Boca Raton, FL, p 303-331

Ulanowicz RE, Norden JS (1990) Symmetrical overhead in flow and networks. Int J Syst Sci 21:429-437

Uye SI (1982) Length-weight relationships of important zooplankton from the Inland Sea of Japan. J Oceanogr Soc Jpn 38:149-158

Valente LMP, Gouveia A, Rema P, Matos J, Gomes EF, Pinto IS (2006) Evaluation of three seaweeds Gracilaria bursa-pastoris, Ulva rigida and Gracilaria cornea as dietary ingredients in European sea bass (Dicentrarchus labrax) juveniles. Aquaculture 252: 85-91

Wiebe PH, Boyd S, Cox JL (1975) Relationships between

Editorial responsibility: Gianluca Sará,

Palermo, Italy zooplankton displacement volume wet weight, dry weight and carbon. Fish Bull 73:777-786

Winemiller KO (1996) Factors driving spatial and temporal variation in aquatic floodplain food webs. In: Polis GA, Winemiller KO (eds) Food webs: integration of patterns and dynamics. Springer, Dordrecht, p 298-312

Ku S, Chen Z, Li C, Huang X, Li S (2011) Assessing the carrying capacity of tilapia in an intertidal mangrove-based polyculture system of Pearl River Delta, China. Ecol Modell 222:846-856

Yonge CM (1949) On the structure and adaptations of the Tellinacea, deposit-feeding Eulamellibranchia. Philos Trans R Soc B 234:29-76

K Zhou B, Dong S, Wang F (2015) Trophic structure and energy fluxes in a grass carp (Ctenopharyngodon idellus) cultured pond ecosystem. Aquacult Int 23:1313-1324

Submitted: February 18, 2020; Accepted: August 31, 2020

Proofs received from author(s): October 28, 2020 